\title{
Effectiveness of oral versus parenteral antibiotics in cesarean section: an observational study
}

\author{
Malini Bharadwaj, Rani R. Momaya*, Rituja Kaushal
}

Department of Obstetrics and Gynecology, L.N. Medical College and J.K. Hospital, Bhopal, Madhya Pradesh, India

Received: 04 October 2020

Revised: 16 November 2020

Accepted: 17 November 2020

*Correspondence:

Dr. Rani R. Momaya,

E-mail: dr.rani.momaya@gmail.com

Copyright: (C) the author(s), publisher and licensee Medip Academy. This is an open-access article distributed under the terms of the Creative Commons Attribution Non-Commercial License, which permits unrestricted non-commercial use, distribution, and reproduction in any medium, provided the original work is properly cited.

\begin{abstract}
Background: Women undergoing caesarean section are associated with high rates of post-operative infections, which causes significant rise in infectious morbidity, duration of hospital stay and cost treatment. Implementation of appropriate antibiotic prophylaxis is desirable to prevent these complications. We aimed to observe the outcome of Intravenous single dose antibiotic prophylaxis pre-operatively followed by oral antibiotics post-operatively, in comparison to other group with multiple dose Intravenous antibiotic prophylaxis post-operatively.

Methods: An observational study conducted in the department of obstetrics and gynaecology, L.N.M.C and J.K. Hospital, Kolar Road, Bhopal, on patients undergoing Elective or Emergency Lower segment caesarean section (LSCS) for a period of 6 months, on 100 subjects, with 50 participants in each group. Null hypothesis was invalidated by statistically analysing the data using chi square test, Unpaired t-test and odds ratio.

Results: Prevalence of c-section was more in 25-31year age group. Abnormal presentation was the most common indication for elective LSCS in both the groups (8\%), non-progress of labour and foetal distress was the most common indication for emergency LSCS in group A and B respectively (10\%). There was statistically insignificant difference in the occurrence of post-operative complications in both the groups (chi sq. value $=0.4285$, $p$ value $=0.5127$ ) with overall, most common complication was febrile morbidity ( $8 \% \mathrm{vs} .12 \%)$. Significant difference noted in total bed occupancy days (unpaired t-test 1.9844) (p-value. $0.000000049<0.05 \%$ ).

Conclusions: We recommend the use of cost-effective single dose antibiotic prophylaxis in prevention of postoperative infectious morbidity in women undergoing caesarean section.
\end{abstract}

Keywords: Caesarean section, Single dose antibiotic prophylaxis, Wound infection

\section{INTRODUCTION}

In today's scenario caesarean section is the single most important risk factor for postpartum maternal infection. ${ }^{1}$ There is 5-20-fold greater risk of infection and infectious morbidity in women undergoing caesarean section as compared to vaginal delivery. ${ }^{1-3}$ It is highly desirable to reduce the rates of surgical site infections (SSI) following caesarean section. As they are associated with significant morbidity and longer duration of hospital stay, which is troublesome in cases of re-admission for a woman trying to cope with both the postoperative period and new-born. ${ }^{4}$

Implementation of proper aseptic and surgical techniques and use of antibiotics as prophylaxis will result in reduction of postoperative wound infections. ${ }^{5}$ Purpose of prophylactic antibiotics is to reduce the bacterial load to a minimum level, so that it enables the patient's immunological defences to function adequately. ${ }^{5,6}$ For antibiotics to be effective the levels should be adequate in tissue at the time of incision. Administration of 
antibiotics before skin incision may reduce the risk of postoperative infection. ${ }^{7}$ Currently in many centres, single dose prophylaxis has not been accepted and multiple dose regimens are still in practice. Recent guidelines and publications suggest that single dose antibiotic prophylaxis is equally effective in clean contaminated surgical procedures. ${ }^{3,5,8}$

There are strong recommendations by WHO guideline panel (2015) regarding the administration of prophylactic antibiotics before skin incision. ${ }^{7,8}$ The GDG also favoured the use of single-dose antibiotic regimens given prior to or during caesarean section, in comparison to multiple-dose regimens which usually extend to the postoperative period. ${ }^{9}$ In 2018 , the American College of Obstetricians and Gynaecologists (ACOG) announced, a new recommendation for antibiotic prophylaxis during caesarean delivery. It states that women undergoing caesarean section should receive antibiotics prophylaxis routinely within 1 hour before the start of surgery and it should be started as soon as possible, in case of an emergency caesarean section. ${ }^{10}$ Rational use of prophylactic antibiotics and ceasing unnecessary use of postoperative antimicrobial prophylaxis, will help in prevention of post-operative infections, reducing the costs, shorten the duration of hospital stay, bed occupancy and development of antibiotic drug resistance. ${ }^{3,5,6}$ Recently, there is desperate increase in demand of hospital beds and increasing cost of medical care have given added incentive to implement effective methods to decrease the post-operative morbidity.

The aim of our study was to observe the effectiveness and outcome of pre-operative single dose Intravenous antibiotic prophylaxis in a group, in comparison to other group who were given multiple dose Intravenous antibiotics post-operatively. Currently, the cochrane database of systemic reviews; ACOG (2018), WHO (2015), GDG recommend narrow range 1st generation Cephalosporin single dose prophylaxis in caesarean sections. $^{8-10}$ In our study we used intravenous cefoperazone (3rd generation cephalosporin) in combination with sulbactum as a prophylactic antibiotic, as resistant pattern of our local population was resistant to multiple antibiotics but was sensitive to cefoperazone. Other factors such as longer half-life, cost effectivity and broad spectrum of activity against microorganisms were taken into consideration. ${ }^{6}$

\section{METHODS}

It was an observational study, conducted in Obstetrics and Gynaecology department of L.N. Medical College and Research centre and associated J.K Hospital, Bhopal. For a period of 6 months, November 2019 to April 2020, after permission from the ethical committee. A well informed and written consent of the patient and relatives were taken. Study was done on 100 patients with 50 patients in each group and selection was based on inclusion and exclusion criteria.
All patients undergoing Lower segment caesarean section (LSCS) on emergency or elective basis were included in the study. Patients with known hypersensitivity to any of the study drugs, BMI $\geq 30$, malnutrition, prolonged preoperative hospitalization, prolonged duration of surgery $>1$ hour, blood loss during surgery $>1$ liter, premature rupture of membranes $>6$ hours, any antibiotic treatment taken 2 weeks prior to surgery, patient with evidence of current infection (fever, foul smelling discharge) or any associated co-morbidities (Hypertension, diabetes or cardiac problem requiring multiple dose antibiotics), presence of chorioamnionitis, anemia or patients in immunocompromised state were excluded from the study.

Detailed history with thorough clinical and obstetrics examination was done. Routine laboratory investigations like complete blood count, urine examination, blood sugar and serology were sent for each patient prior to the procedure. Sensitivity testing was done before 1st dose of antibiotics in both the groups.

Prospective study was done on group A, they were given single dose of Injection cefoperazone $1 \mathrm{gm}$ (3rd generation cephalosporins) in combination with sulbactum $500 \mathrm{mg}$ (ß-lactamase inhibitor) intravenous, perioperatively $30-60$ minutes before the skin incision, followed by patients were checked for bowel sounds at 6 hours post-operative period and were given antibiotics in the form of tablet metronidazole $400 \mathrm{mg} 8$ hourly and tablet cefuroxime $500 \mathrm{mg} 12$ hourly, till stitch removal.

While in Group B collection of data was retrospective, during study period. Included patients, who were given single dose of injection cefoperazone $1 \mathrm{gm}$ in combination with sulbactum $500 \mathrm{mg}$ Intravenous, perioperatively 30-60 minutes before the skin incision, followed by post operatively intravenous cefoperazone 1 gm in combination with sulbactum $500 \mathrm{mg} 12$ hourly and injection metronidazole $500 \mathrm{mg}$ every 8 hourly for 3 days followed by tablet metronidazole $400 \mathrm{mg} 8$ hourly and tablet cefuroxime $500 \mathrm{mg} 12$ hourly given for 5 days. Patients in study group A were not given any other Intravenous or oral antibiotics. Other medications were administered depending upon the clinical condition and need of patients, such medications like analgesics and proton pump inhibitors.

\section{Follow up}

Patients were reviewed for any indication of infection or febrile morbidity, within first 6 hours of post-operative period and 12 hourly on post-operative day 1,2 , and 3 . Observation was done by examination of vitals (temperature, pulse, blood pressure and respiratory rate), size of the uterus, condition of incision wound or presence of tenderness, amount, colour and smell of the lochia. Urinary catheter was removed, after 6 hours postop period. On 3rd post-operative day complete hemogram 
and urine routine and microscopy were done in all the patients.

Primary outcomes were observed in terms of febrile morbidity, defined as an oral temperature of $>38^{\circ} \mathrm{C}$ on two occasions at least four hours apart, excluding the first 24 hours post-operatively; causes were ruled out including endometritis (fever, foul smelling lochia, and uterine tenderness with or without positive high vaginal swab culture), wound infection (fever, tenderness, induration, exudates), pelvic abscess, urinary tract infections, chest infections, catheter related infections, thrombophlebitis at the cannula site. Once febrile morbidity was identified, patients were examined thoroughly to localize the potential source of infection. Urine analysis and total white blood cell count and other required investigations were sent. Thereafter check dressing was done on post-op day 3 and day 5. Inspection of wound was done for soakage, tenderness, induration, wound dehiscence, discharge over the operated site. Skin sutures were removed on the 7th postoperative day, except in cases with wound infection. Patients with superficial wound infections were treated with dressing only and deep ones were treated with dressing and resuturing. Antibiotics were added according to culture and sensitivity. Patients were followed till 1 week after discharge and were instructed to contact if any signs and symptoms of infection occur. Study was terminated if patient develops any complication which requires additional treatment. Outcomes were also measured in terms of bed occupancy and cost effectiveness in both the groups. All chosen statistical tests were done with a confidence interval of $95 \%$ and alpha error $=5 \%$.

\section{RESULTS}

Total 100 patients were enrolled in our study. With 50 patients in each group respectively. On comparing baseline characteristics of both the groups (Table 1), more than half of the patients $(60 \%$ in group A, 52\% in group B) were in 25-31 year of age group and maximum were gravida 1 (32\% in group A, $38 \%$ in group B).

Table 1: Baseline characteristics.

\begin{tabular}{|lllll|}
\hline $\begin{array}{l}\text { Age } \\
\text { (years) }\end{array}$ & Group A & $\%$ & Group B & $\%$ \\
\hline $\mathbf{1 8 - 2 4}$ & 20 & 40 & 16 & 32 \\
\hline $\mathbf{2 5 - 3 1}$ & 30 & 60 & 26 & 52 \\
\hline $\mathbf{3 2 - 3 7}$ & 0 & 0 & 8 & 16 \\
\hline Mean \pm SD & $25.16 \pm 3.138$ & & $27.04 \pm 4.444$ & \\
\hline Parity & & & & 38 \\
\hline Gravida 1 & 16 & 32 & 19 & 34 \\
\hline Gravida 2 & 15 & 30 & 17 & 18 \\
\hline Gravida 3 & 13 & 26 & 9 & 10 \\
\hline Gravida 4 & 6 & 12 & 5 & \\
\hline
\end{tabular}

Group A n (number)=50, Group B n=50
Table 2: Type of lower segment caesarean section (LSCS).

\begin{tabular}{|lll|}
\hline Type of LSCS & Group A & Group B \\
\hline Elective LSCS & 26 & 24 \\
\hline Emergency LSCS & 24 & 26 \\
\hline
\end{tabular}

Group A n=50, Group B n=50

Table 3: Indications for LSCS.

\begin{tabular}{|c|c|c|}
\hline Indications & Group A & Group B \\
\hline \multicolumn{3}{|l|}{ Elective caesarean } \\
\hline $\begin{array}{l}\text { Previous LSCS + Cephalopelvic } \\
\text { disproportion (CPD) }\end{array}$ & 3 & 3 \\
\hline $\begin{array}{l}\text { Previous LSCS + Bad obstetrics } \\
\text { history }\end{array}$ & 3 & 1 \\
\hline $\begin{array}{l}\text { Previous LSCS + Foetal growth } \\
\text { restriction }\end{array}$ & 1 & 1 \\
\hline Previous 2 LSCS & 3 & 2 \\
\hline CPD & 3 & 2 \\
\hline $\begin{array}{l}\text { Previous LSCS + abnormal } \\
\text { presentation }\end{array}$ & 0 & 2 \\
\hline $\begin{array}{l}\text { Abnormal presentation } \\
\text { (Transverse or Oblique Lie) }\end{array}$ & 4 & 4 \\
\hline Primigravida + breech & 2 & 3 \\
\hline $\begin{array}{l}\text { Precious pregnancy }+ \text { deranged } \\
\text { colour doppler }\end{array}$ & 1 & 1 \\
\hline $\begin{array}{l}\text { Precious pregnancy }+ \text { bad } \\
\text { obstetrics history }\end{array}$ & 1 & 2 \\
\hline On maternal request & 2 & 1 \\
\hline $\begin{array}{l}\text { Foetal growth restriction }+ \\
\text { deranged colour doppler }\end{array}$ & 1 & 1 \\
\hline $\begin{array}{l}\text { Foetal growth restriction }+ \\
\text { severe oligohydroamnios }\end{array}$ & 1 & 0 \\
\hline Cervical fibroid & 1 & 1 \\
\hline \multicolumn{3}{|l|}{ Emergency } \\
\hline $\begin{array}{l}\text { Failed induction of labour }+ \\
\text { Non-progress of labour }\end{array}$ & 5 & 2 \\
\hline $\begin{array}{l}\text { Non-progress of labour }+ \\
\text { Abnormal presentation }\end{array}$ & 3 & 0 \\
\hline $\begin{array}{l}\text { Previous LSCS + Features of } \\
\text { Scar dehiscence/Scar tenderness }\end{array}$ & 1 & 3 \\
\hline Previous LSCS + Foetal distress & 1 & 2 \\
\hline Foetal distress & 4 & 5 \\
\hline Foetal distresss + Oligohydroamni & 0 & 4 \\
\hline $\begin{array}{l}\text { Foetal distress + deranged } \\
\text { colour doppler }\end{array}$ & 3 & 2 \\
\hline $\begin{array}{l}\text { Foetal growth restriction }+ \\
\text { foetal distress }\end{array}$ & 1 & 2 \\
\hline Dystocia + Foetal Distress & 1 & 1 \\
\hline Occipito-posterior + big size baby & 1 & 1 \\
\hline Deep transverse arrest & 3 & 2 \\
\hline CPD With leaking per vagina & 1 & 2 \\
\hline
\end{tabular}

Distribution of population according to modified Kuppuswamy socioeconomic scale in both the groups were found to be statistically insignificant (Chi sq. value 
4.5111, p-value 0.341). Group A and B had 52\% and $48 \%$ of elective LSCS, while there was $48 \%$ and $52 \%$ of Emergency section in both the groups, respectively (Table 2) (chi sq. value $=0.0795$, p-value $=0.7779$ ). Abnormal presentation was the most common indication for elective LSCS, in both the groups and failed induction or nonprogress of labour was the most common indication for emergency section in group A, while foetal distress was most common indication in group B (Table 3 ).

It was statistically analysed that there was no significant difference in the occurrence of post-operative complications in both the groups. Total 6 patients in group A and 8 patients in group B had wound infections. While 2 patients in group A and 3 patients in Group B had fever post operatively (chi sq. value $=0.4285$, p-value $=0.5127$ ). Overall, most commonly observed postoperative complication was febrile morbidity (Table 4, 5).

Table 4: Post-operative complications in both the groups.

\begin{tabular}{|lllll|}
\hline Complications & Group A & $\%$ & Group B & $\%$ \\
\hline Fever & 2 & 4 & 3 & 6 \\
\hline Wound infection & & & & \\
\hline Induration & 2 & 4 & 2 & 4 \\
\hline Tenderness & 1 & 2 & 1 & 2 \\
\hline Discharge & 2 & 4 & 2 & 4 \\
\hline Gaping & 1 & 2 & 2 & 4 \\
\hline $\begin{array}{l}\text { Gaping requiring } \\
\text { resuturing }\end{array}$ & 2 & 1 & 2 \\
\hline $\begin{array}{l}\text { Urinary tract } \\
\text { infection }\end{array}$ & 1 & 2 & 1 & 2 \\
\hline $\begin{array}{l}\text { Respiratory tract } \\
\text { infection }\end{array}$ & 2 & 4 & 1 & 2 \\
\hline Thrombophlebitis & 2 & 4 & 1 & 2 \\
\hline
\end{tabular}

Group A n=50, Group B n=50

Table 5: Presence of infection according to type of LSCS.

\begin{tabular}{|lll|}
\hline Type of LSCS & $\begin{array}{l}\text { Infection present } \\
\text { in Group A }\end{array}$ & $\begin{array}{l}\text { Infection presen } \\
\text { in Group B }\end{array}$ \\
\hline Elective section & 1 & 2 \\
\hline $\begin{array}{l}\text { Emergency } \\
\text { section }\end{array}$ & 5 & 6 \\
\hline
\end{tabular}

Group A n=50, Group B n=50

We found statistically insignificant difference in presence of infection according to the type of LSCS, with Chi sq. value $=0.1414$, $\mathrm{p}$-value $=0.7068$ (Table 5). Though, odds ratio (OR) for post-operative fever and overall postoperative infection in group A vs. group B, was 0.6527 and 0.7159 , respectively.

However, a significant difference was noted in the distribution of data regarding total bed occupancy days. On applying unpaired t-test (1.9844) for the available data, p-value obtained was $(0.000000049<0.05 \%)$. It depicts that bed occupancy days were comparatively lesser in group A and thus single dose prophylaxis group was found cost effective.

\section{DISCUSSION}

In our country, rates of postoperative infections are higher in obstetrics patients in comparison to other specialities. The main reason stays majority of unbooked patients and poor socioeconomic status. Therefore, prevention is an important aspect in these patients. Many studies and articles have reported that use of prophylactic antibiotics can effectively prevent the postoperative infection.

It is recommended to administer prophylactic antibiotic pre-operatively before tissue injury, so that it achieves a high plasma concentration during the procedure and prevents the bacterial contamination. ${ }^{5,8,9}$ A new WHO guidance on prevention and treatment of maternal peripartum infections, published in 2015 made strong recommendations regarding the administration of prophylactic antibiotics before skin incision, rather than after umbilical cord clamping, for women undergoing elective or emergency caesarean section. ${ }^{7}$ Damini et al, in a single-blind randomised clinical trial, also, found that risk of overall postoperative infection was significantly lower when prophylaxis was given within an hour before incision (RR 0.77, 95\% CI 0.62-0.97). ${ }^{1}$

Though the pre-incision antibiotic prophylaxis would risk the exposure of neonate to antibiotic before birth. In literature, even the limited exposure might interfere with the evaluation of new born for sepsis. ${ }^{11}$ However, a twopart prospective study over the period of two years, was done by Brown et al shows that by changing the timing of antibiotic prophylaxis from after cord clamping to preincision, surgical site infection (SSI) rates dropped from $10.8 \%$ to $2.8 \%$ and there was no adverse neonatal consequences. $^{4}$

Risk of postoperative wound infection can be decreased by practicing appropriate measures like pre-operative baths, changing into sterile gowns before the procedure, surgical asepsis, disposables gowns etc. postoperative wound infection can be superficial or deep; superficial occurring above the fascia and deep occurring below the fascia. In our study we observed, the overall incidence of wound infection was lower in the single dose group, but the association was statistically insignificant ( $p$ value $=0.7068$ ). However, findings were in agreement with an open label randomized controlled trial study done by, Gideon et al and Kiondo et al, to compare the incidence of post-operative infections among single dose pre-operative Ceftriaxone and Metronidazole compared to multiple doses after delivery by elective caesarean section, concluded, that there was no significant differences in the incidence of post-operative wound infections between the single dose versus multiple dose arm (RR 1.895; 95\% CI (0.2-21.4). Also, they did not 
find any clinical endometritis and febrile morbidity during their 14 days of follow up period. ${ }^{3}$ Which contrasted with our study. We observed that, following antibiotic prophylaxis, most common post-operative complication was febrile morbidity $(10 \%)$ in both the groups (4\% versus 6\%), we did not observe any significant difference in overall incidence of respiratory tract infections (4\% vs. $2 \%$ ) and thrombophlebitis (4\% vs. $2 \%$ ) in both the groups.

As observed by Mohan et al. in a descriptive crosssectional study, overall incidence of post-operative fever was higher in obstetrics patients, $5.81 \%$ and lesser no. of wound infections were $(2.33 \%)$ observed also, there was no UTI or respiratory tract infection. ${ }^{5}$ In our observation total $4 \%$ of UTI cases were observed in both the groups ( $2 \%$ vs. $2 \%$ ). Kumari et al. in a prospective single blind study, found $1.81 \%$ of febrile morbidity, with overall highest incidence of UTI $(4.54 \%){ }^{6}$ Prathima et al. in a prospective comparative study found more incidence of UTI in multiple dose group ( $p$-value $=0.103$ ), with no statistically significant difference in incidence of fever in both the groups ( $p$ value $=0.45$ and 0.83 ), also, there was no difference in the outcome of wound infection ( $p$ value $=0.505$ and 0.639$){ }^{11}$

Various combinations of antibiotics are used nowadays. It is observed that unnecessary use of antibiotics results in emergence of resistant organisms, it also leads to economic burden on our health system, especially in this desperate time. So, choice of antibiotics should be in consideration of the factors such as cost effectivity. ${ }^{11} \mathrm{~A}$ prospective randomized controlled study done by Zeel et al. Showed that the average cost in the single dose group was significantly less then multiple dose group ( $\mathrm{p}$-value of 0.0001 ), which was in consistency with our results. ${ }^{2}$

Our study observed a significant difference in bed occupancy and hospital stay in both the groups. On applying unpaired t test (1.9844) for the available data, $\mathrm{p}$ value obtained was $(0.000000049<0.05 \%)$. But results were in disagreement with a interventional quasi experimental study done by Shaheen et al, who found that duration of hospital stay was 6 days or less in $45(90 \%)$ patients each and more than 6 days in $5(10 \%)$ patients each in both the groups and concluded that hospital stay was almost same in both the groups, with no significant difference. $^{12}$ Our results were also in contrast with a prospective randomized controlled study, done by Zeel et al with no statistically significant difference in average duration of hospital stay in both the groups. The duration in the single dose group was $8.4 \pm 3.3$ days while in the multiple dose group was $8.1 \pm 2.9$ days. $^{2}$

Our outcomes were in similarity with the studies done by Shaheen et al $(\mathrm{OR}=1)$, Prathima et al. $(\mathrm{p}=0.45$ and 0.83$)$ and Ansari et al. (p-value 0.50), we did not find any statistically significant difference in post-operative infection outcome of both the groups (Chi square value $=0.1414, p=0.7068$ ), thus we recommend the use of single dose regimen which is as effective as multiple drug regimen. ${ }^{11-13}$

\section{Limitations}

Our smaller sample size; wider study population is needed for significant results. Also, our study lacked the parameters to assess the neonatal outcome, more studies are required to procure the data.

\section{CONCLUSION}

Our study concluded that administration of single dose antibiotic prophylaxis was equally efficacious as multiple dose antibiotics in preventing postoperative complications in caesarean section. There was no significant difference in the outcome of both the groups. Also, the resistance of microorganisms, compliance and cost effective are the factors that can be significantly reduced on implementation of single dose antibiotic prophylaxis.

\section{Funding: No funding sources \\ Conflict of interest: None declared}

Ethical approval: The study was approved by the Institutional Ethics Committee

\section{REFERENCES}

1. Dlamini LD, Sekikubo M, Tumukunde J. Antibiotic prophylaxis for caesarean section at a Ugandan hospital: a randomised clinical trial evaluating the effect of administration time on the incidence of postoperative infections. BMC Pregnancy Childbirth. 2015;15:91.

2. Shah Z, Kshirsagar NS, Shah S. Comparison of single dose prophylactic antibiotics versus five days antibiotic in cesarean section. J Evolution Med Dental Sci. 2014;3(12):24.

3. Mugisa GA, Kiondo P, Namagembe I. Single dose ceftriaxone and metronidazole versus multiple doses for antibiotic prophylaxis at elective caesarean section in Mulago hospital: a randomized clinical trial version 1; peer review: 1 approved, 1 approved with reservations. Available at https://doi.org/10.12688/aasopenres. 12849.1. Accessed on 02 September 2020.

4. Brown J, Thompson M, Sinnya S. Pre-incision antibiotic prophylaxis reduces the incidence of postcaesarean surgical site infection. J Hosp Infect. 2013;83(1):68-70.

5. Mohan J, Thangaroja T, Menon M. Single dose antibiotic prophylaxis in elective obstetric and gynaecological surgeries-a descriptive study. Int J Reprod Contracept Obstet Gynecol. 2017;6:3897-02.

6. Kumari R, Sharma A, Sheetal, Roy P, Anupriya. To study the effectiveness of prophylactic use of ceftriaxone (single dose) in caesarean section in low risk patients in a tertiary care center, Moradabad, India. Int J Res Med Sci. 2017;5:5278-82. 
7. New WHO guidance on prevention and treatment of maternal peripartum infections. Available at http://dx.doi.org/10.1016/ S2214-109X(15)00213-2. Accessed on 29 September 2015.

8. WHO recommendation on routine antibiotic prophylaxis for women undergoing elective or emergency caesarean section (September 2015). The WHO Reproductive Health Library; Geneva: World Health Organization. Available at https:// extranet. who. int/ rhl/ topics/ preconception-pregnancychildbirth- and- postpartum- care/whorecommendation- antibiotic- prophylaxis- caesareansection-using-single-dose-first-generation. Accessed on 20 August 2020.

9. WHO recommendation on antibiotic prophylaxis for caesarean section using a single dose of first generation cephalosporin or penicillin in preference to other classes of antibiotics (September 2015). The WHO Reproductive Health Library; Geneva: World Health Organization. Available at https://extranet.who.int/rhl/topics/preconceptionpregnancy-childbirth-and-postpartum-care/whorecommendation-antibiotic-prophylaxis-caesareansection-using-single-dose-first-generation Accessed on 20 August 2020.

10. Committee on Practice Bulletins-Obstetrics. ACOG Practice Bulletin No. 199: Use of prophylactic antibiotics in labor and delivery. Obstet Gynecol. 2018;132(3):103-19.

11. Prathima S, Savitha C, Tejeswini KK, Anitha GS. Comparative study of single dose versus multiple doses of antibiotic prophylaxis in caesarean delivery. Int J Reprod Contracept Obstet Gynecol. 2017;6:215-8.

12. Shaheen S, Akhtar S. Comparison of single dose versus multiple doses of anitibiotic prophylaxis in elective caesarian. J Postgrad Med Inst. 2014;28(1):83-6.

13. Ansari N, Das C, Ansari M. Evaluation of prophylactic antibiotic in caesarean section. J Nepalgunj Med College. 2015;12(2):40-1.

14. Kamilya, Gourisankar. A randomized controlled trial comparing two different antibiotic regimens for prophylaxis at cesarean section. J Obst Gynaecol India. 2012;62(1):35-8.

15. Francis C, Mumford M, Strand M. Timing of prophylactic antibiotic at cesarean section: a doubleblinded, randomized trial. J Perinatol. 2013;33:75962.

16. Smaill FM, Grivell RM. Antibiotic prophylaxis versus no prophylaxis for preventing infection after cesarean section. Cochrane Database Syst Rev. 2014;(10):CD007482.

17. Martin EK, Beckmann MM, Barnsbee LN, Halton KA, Merollini K, Graves N. Best practice perioperative strategies and surgical techniques for preventing caesarean section surgical site infections: a systematic review of reviews and meta-analyses. BJOG. 2018;125(8):956-64.

18. Vathana M, Muhunthan K. A randomized control trial of single dose versus multiple doses of IV antibiotic prophylaxis in caesarean delivery. Sri Lanka J Obst Gynaecol. 2018;40(4):92-100.

19. Lopes, Rui, Pinto S, Bernardo, Azevedo, Luís. Single dose versus multiple dose of antibiotic prophylaxis in caesarean section: a systematic review and metaanalysis. Int J Obst Gynaecol. 2016;124:10-4.

Cite this article as: Bharadwaj M, Momaya RR, Kaushal R. Effectiveness of oral versus parenteral antibiotics in cesarean section: an observational study. Int J Reprod Contracept Obstet Gynecol 2021;10:186-91. 